\title{
CUT: Perfil dos dirigentes e resposta sindical frente à reforma trabahista
}

\section{Fernanda Forte de Carvalho* (D) Jonas Tomazi Bicev ${ }^{* *}$ (D)}

\section{Resumo}

Neste artigo, apresentamos aspectos da composição social da Central Única dos Trabalhadores (CUT), comparando seus congressos, do $10^{\circ}$ CONCUT ao $13^{\circ}$ CONCUT, compreendendo o período 2009-19. Destacamos características do perfil dos dirigentes sindicais ligados a essa central e as primeiras respostas do sindicalismo frente à reforma trabalhista, conforme pesquisas aplicadas na ocasião dos congressos da CUT, sem perder de vista o cenário da pandemia - Covid 19. Nas considerações finais apontamos alguns dos principais desafios que a CUT enfrenta na atualidade.

Palavras-chave: Central Única dos Trabalhadores, composição social da CUT, reforma trabalhista.

\section{CUT: Profile of leaders and union response to labor reform}

\section{Abstract}

In this article we present aspects of the social composition of Central Única dos Trabalhadores (CUT Brazil) by comparing its general meetings, from the 10th to the 13th, held from 2009 to 2019. We highlight characteristics of the profile of union leaders who belong to this trade union and the first responses of trade unionists to labor reform, according to research applied at the time of the CUT general meetings, without losing sight of the pandemic scenario - Covid 19. In the final considerations we point out some of the main challenges that CUT faces today.

Keywords: Central Única dos Trabalhadores, social composition, labor reform.

* Universidade Estadual de Londrina, Londrina, PR, Brasil.

** Centro de Estudos da Cultura Contemporânea, São Paulo, SP, Brasil. 


\section{Introdução}

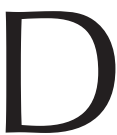

esde 2015, quando a prolongada instabilidade política e econômica e os efeitos da reforma trabalhista (Lei 13.467 de 2017) realçaram as fragilidades estruturais do movimento sindical brasileiro, palavras como revitalização, reorganização ou renovação dos sindicatos tornaram-se recorrentes no discurso de importantes lideranças sindicais do país. Esse discurso - que, muitas vezes, resulta em ações, mas nem sempre é capaz de sustentar mudanças organizacionais abrangentes - consiste em tentativas de reagir não somente à reforma trabalhista em curso, como também aos processos de globalização e ao enfraquecimento da capacidade de regulação exercida pelo sindicalismo no plano nacional. Aliás, a nosso ver, esse debate pode ser associado ao desenvolvimento de estratégias de revitalização sindical (Frege; Kelly, 2004) que, na CUT, teve início em 2015, a partir de um projeto ${ }^{1}$ (descontinuado por decisão da própria central) cujo foco era identificar estratégias sindicais internacionais inovadoras, capazes de transformar ameaças em oportunidades (Kloosterboer, 2008; GumbrellMcCornick; Hyman, 2013).

Há muito a literatura internacional tem destacado o perfil predominantemente masculino e a idade avançada dos dirigentes sindicais, em função das barreiras socioculturais existentes à participação política feminina e à inclusão de jovens em postos de direção. Mas esse perfil também pode ser um efeito da própria estrutura interna dos sindicatos (Frege; Kelly, 2004), de caráter burocrático e pouco permeável à mudança na composição social das direções. Além disso, organizados inicialmente a partir de setores da indústria, da administração pública e de serviços típicos da sociedade urbana-industrial, grande parte dos postos de comando dessas

${ }^{1}$ O Projeto Sindicalismo no século XXI: desafios e experiências de revitalização pretendia identificar experiências internacionais inovadoras, embasadas nas estratégias de revitalização sindical propostas em Carola Frege e John Kelly (2004), a saber: organização e recrutamento de novos membros (organizing), parceria sindicatos-empregadores (labour-management partnership), ação política (political action), reforma das estruturas sindicais (reform of union structures), construção de coligações (coalition-building) e solidariedade internacional (international solidarity). 
organizações ainda é ocupada por trabalhadores formados politicamente nas disputas e negociações coletivas existentes nos setores organizados da economia, em que prevalece o emprego formal e a contratação direta e de longa duração (Rodrigues, L., 2002). Logo, há dificuldades em inspirar confiança e retratar os atuais anseios dos trabalhadores atingidos pela uberização que, apesar da aparência de prestação de serviços, oblitera relações de assalariamento e de exploração do trabalho (Antunes, 2020).

Em seu trabalho clássico sobre os três tipos puros de dominação legítima, Max Weber (2008 [1921]) já destacava que a ascensão de lideranças políticas é um fenômeno sociológico complexo que envolve a combinação de cada uma das três dimensões que legitimam o exercício do poder: a dominação racionallegal ou burocrática (em que a autoridade é uma propriedade do cargo, ocupado por um profissional, avaliado de acordo com regras estatuídas); a tradição (baseada no respeito aos poderes senhoriais e o "reconhecimento" de um estatuto como "válido desde sempre"); e o carisma (em que autoridade pertence "à pessoa do líder por suas qualidades excepcionais e não em virtude de sua posição estatuída ou de sua dignidade tradicional" (Weber, 2008, p. 135). Mais do que destacar os fundamentos da legitimidade do poder, o autor já demonstrava a tensão existente nas organizações burocráticas contemporâneas, em que a obediência às regras formais, estabelecidas de modo racional, e a execução de tarefas com a menor influência possível dos motivos pessoais ou sentimentais favoreciam a ascensão do profissional e delimitavam o espaço para o surgimento de lideranças carismáticas capazes de inovar, reformar e renovar a confiança nas instituições.

Este artigo consiste em uma primeira aproximação e discussão sobre a composição social da maior central sindical brasileira, a CUT (Central Única dos Trabalhadores) no período 2009-19. Ao comparar as informações quantitativas extraídas de pesquisas ${ }^{2}$ sobre o perfil sociodemográfico e

${ }^{2}$ Nos $10^{\circ}, 12^{\circ}$ e $13^{\circ}$ CONCUTs (2009, 2015 e 2019) participaram 2.299, 2.154 e 1.705 delegados, respectivamente. Seguindo esta ordem cronológica, o percentual de questionários respondidos e validados foi de $82,5 \%, 78,5 \%$ e $65 \%$. Já no 11 o CONCUT (2012), foram credenciados 2.322 delegados e a pesquisa se organizou por meio de amostra estatística, composta por 1.270 delegados, com margem de erro de $2 \%$ para mais ou para menos e nível de confiança de 95\% (CUT, 2010, 2013, 2016, 2020). 
político dos delegados dos quatro últimos Congressos Nacionais da CUT (CONCUT), pretendemos identificar tanto a estabilidade quanto as mudanças no perfil dos líderes sindicais nos últimos anos e os efeitos da crise sindical desencadeada pela reforma trabalhista no posicionamento político de seus membros, participantes dos congressos.

Na primeira seção, recuperamos os principais momentos da atuação social e política dessa central, com destaque para a passagem da CUT movimento para a CUT instituição, da atuação cidadã para a institucional, do diálogo para o conflito e oposição. Na segunda seção, destacamos as principais características sociodemográficas, o perfil das lideranças e o posicionamento em relação às mudanças introduzidas pela reforma trabalhista. Por fim, em forma de conclusão, buscamos identificar o quanto a CUT, nos últimos anos, esteve aberta a uma renovação da composição social da sua direção e a sua capacidade de resposta à reforma trabalhista; lançando alguns desafios de renovação do sindicalismo ligado à CUT, discutimos os achados à luz da teoria sociológica, nesse caso, com foco em alguns dos recursos de poder (estrutural, associativo, institucional e societal) conforme a tipologia de Costa et al. (2020).

\section{CUT: trajetória de atuação política e social}

A CUT $^{3}$ é fruto da ação do novo sindicalismo e das greves e mobilizações iniciadas no final da década de 1970. De tal movimento de renovação sindical destaca-se a ação do Sindicato dos Metalúrgicos de São Bernardo que, tendo Lula à frente, pouco a pouco foi atuando por dentro da estrutura sindical, reivindicando direitos, articulando-se a novos movimentos sociais e, assim, politizando espaços antes silenciados na esfera privada (Sader,

\footnotetext{
${ }^{3}$ A CUT foi fundada em 1983, com o objetivo de mudar a estrutura sindical a partir da luta por liberdade e autonomia sindical. Na estrutura organizativa da CUT, vigoram estratégias organizativas por ramos (Comércio e Serviços; Seguridade Social; Profissionais Liberais; Vestuário; Educação; Construção e Madeira; Urbanitário; Alimentação; Financeiro; Metalúrgico; Aposentados; Químico; Rural; Comunicação e Informação; Administração Pública; Transporte e Municipais) e por macrossetores (Indústria; Comércio e Serviços; Rural e Serviço Público) (CUT, 2012).
} 
1988). De tal sindicalismo de movimento resultaram reivindicações por abertura democrática do país, democratização das relações de trabalho, assim como por mudanças na estrutura sindical, visando alterar aspectos da prática sindical corporativista, colaboracionista e dependente do Estado (Antunes, 1995).

A composição social da CUT agrupa majoritariamente dirigentes filiados ao Partido dos Trabalhadores (PT) (Rodrigues, L., 1990; Rodrigues, I., 1997; Carvalho, G., 2014; Carvalho, F., 2013, 2014; Carvalho; Costa, 2019). Em 1988, na ocasião do 3 o Congresso Nacional da CUT (CONCUT), o grupo político majoritário nessa central sindical, a Articulação Sindical, conseguiu aprovar mudanças estatutárias que restringiram, sobretudo, a proporção de delegados de base e o peso das oposições sindicais nos seus congressos. A partir desse evento, a CUT foi alçada à condição de Central Sindical (e não de movimento social), aproximando-se dos modelos sindicais socialdemocratas, presentes em países europeus (Lopes Neto; Gianotti, 1993; Véras de Oliveira, 2002). Daí, criaram-se as bases para o exercício de uma prática sindical menos movimentista e mais institucional (Rodrigues, I., 1997) cuja marca é o seu caráter propositivo (CUT, 1991), sendo a Câmara Setorial Automotiva, em 1992, um dos exemplos que pode receber maior destaque, não obstante a sua "generalização difícil" (Mello e Silva, 2000).

Em suma, tendo como baliza a inserção do conceito de sindicato cidadão e a adoção de um padrão de ação menos conflitivo em relação aos empresários e governos (Véras de Oliveira, 2002), o grupo político majoritário na CUT, a Articulação Sindical, passou a propugnar um tipo de ação sindical articulada em torno de dois eixos, a saber: resistência propositiva e disputa de hegemonia na sociedade (Carvalho, 2013). Essa estratégia foi alargada, principalmente no período dos governos do PT (2003-16), por meio da participação na governança pública e das amplas relações com a sociedade civil, realidade que veio a reforçar a luta pela ampliação de direitos (Carvalho, 2013; Antunes; Silva, 2015; Ladosky; Rodrigues, 2018; Krein; Dias, 2018; Carvalho; Costa, 2019; Rodrigues et al., 2019). 
Para Nascimento (1998) e Véras de Oliveira (2002), o sindicato cidadão busca fazer um elo de ligação entre os tradicionais e os novos campos de ação, por meio de maior abertura para a sociedade civil, da vocalização das demandas de segmentos até então excluídos da representação sindical, da adoção de formas socioculturais e articulação com movimentos e outros segmentos sociais, propondo a construção de uma cidadania fora do espaço da produção com ações próximas do exercício de um sindicalismo de movimento social ou de um novo sindicalismo social (Lambert; Webster, 1988; Moody, 1997, Munck, 1988; Scipes, 1992; Seidman, 1994; Tapia; Alberti, 2018, Waterman, 2005, 2012 apud Costa et al., 2020). Já, para Galvão (2006, 2009), o sindicalismo cidadão, operacionalizado pela CUT a partir da década de 1990, corresponde a um tipo de prática negocial marcada por concessões ao governo e ao capital.

Tal realidade, de acordo com Antunes e Silva (2015), teria se intensificado no período dos governos do PT, produzindo um tipo de sindicalismo negocial de estado marcado pela dependência estatal - política, ideológica e financeira - intensificada a partir do reconhecimento jurídico das centrais (Lei no 11.648) que ampliou a inclusão em espaços de participação social e permitiu o acesso ao imposto sindical. Já, para Cardoso (2015), Rodrigues et al. (2016) e Ladosky e Rodrigues (2018), esse reconhecimento reforçou a representatividade sindical em função da capacidade institucional do sindicalismo de intervir perante o Estado nos governos do PT. Contudo, não houve um estreitamento da relação das cúpulas sindicais com suas bases ou aumento do associativismo. Por sinal, de acordo com os dados da Pesquisa Nacional de Amostra por Domicílios - PNAD, do IBGE, a taxa de sindicalização (isto é, a parcela da população sindicalizada, em relação ao total da população ocupada na semana de referência) manteve-se relativamente estável em torno de 16\% de 2012 até 2016.

O efeito imediato desse reordenamento sindical no período dos governos do PT foi a intensificação da pulverização e da concorrência sindical e, no caso da CUT, o imposto arrecadado serviu para custear as eleições, oposições sindicais e os processos relacionados à criação de novos 
sindicatos e dados cadastrais, de acordo com a política de aferição da representatividade (Carvalho, 2013; Carvalho; Costa, 2019). Tal processo se fez sem alterar os pilares da estrutura sindical, a saber: unicidade (veda a criação de mais de uma entidade na mesma base territorial); e reconhecimento outorgado pelo Estado, dinâmica presente na estrutura sindical brasileira desde a década de 1940, com a integração do sindicato marginal na própria instituição do Estado (Simão, 2012).

Esse quadro mudou após o golpe parlamentar de abril de 2016, momento em que a convergência de juízes, imprensa e políticos, respaldados no apoio das classes médias e de parte da população de baixa renda que aderiu à rejeição da política ou à antipolítica (Santos, 2017; Avritzer, 2019) culminou no impeachment de Dilma Rousseff (PT), em agosto desse mesmo ano. Desde então, a CUT assumiu publicamente a posição de oposição ao governo do então presidente Michel Temer, filiado ao Movimento Democrático Brasileiro (MDB). Em suma, a CUT cunhou bandeiras tais como: "Eleições Gerais, Fora Temer"; "Não a PEC do fim do mundo", referindo-se à Emenda Constitucional no 95, responsável pelo congelamento dos gastos públicos não financeiros por 20 anos; "Contra a Reforma da Previdência"; abraçou a Campanha "LULA Livre" e converteu a pauta sindical numa agenda em defesa do ex-presidente; mais recentemente, está defendendo o "Impeachment Já, Fora Bolsonaro", presidente eleito em 2018 pelo Partido Social Liberal (PSL) e atualmente sem filiação partidária.

Além disso, a CUT tem reforçado a campanha "Nenhum direito a menos! Pela revogação da antirreforma trabalhista" que vem implantando medidas que visam à flexibilização de direitos trabalhistas, a redução do papel da Justiça do Trabalho e o enfraquecimento dos sindicatos, instituindo um padrão de regulação social do trabalho de viés liberal (Dieese, 2017; Galvão et al., 2017; Krein, 2018; Oliveira et al., 2019) com início no governo Temer. De fato, desde a sua aprovação em 2017, as fragilidades do sindicalismo brasileiro vêm sendo mais expostas e, sem dúvida, há um processo de crise ainda em curso (Rodrigues, L., 2002) cuja leitura não se pode reduzir à mera cooptação do movimento sindical pelos governos do PT. 
Afinal, de acordo com Cardoso (2015), o PT, a CUT e o Movimento Sem Terra (MST) chegaram juntos ao poder, com o início do Governo Lula, em 2003. Sendo assim, o autor adverte que é preciso distinguir, analiticamente, "a crise propriamente sindical, que resulta também das escolhas estratégicas de suas principais lideranças, da crise política ora vivida, que é profunda e afeta todo o campo sindical e a esquerda de um modo geral" (Cardoso, 2015, p. 505). De forma complementar, para Avritzer (2019), há uma crise política marcada, sobretudo, pela regressão da democracia brasileira, principalmente após as manifestações de junho de 2013, resultando numa forte diminuição do apoio dos brasileiros à democracia, ao sistema político e às suas instituições, processo que culminou com a vitória de Jair Bolsonaro em 2018.

Uma das facetas mais aparentes dessa crise que assola o campo sindical nacional é a problemática situação financeira dessas instituições após a reforma trabalhista, pois, com o fim da obrigatoriedade do imposto "quando se compara a arrecadação da contribuição sindical do mês de abril de 2018 à de abril de 2017, nota-se queda da ordem de 90\%. Entre as Centrais, a CUT ${ }^{4}$ foi a que registrou a maior redução da receita (queda de 94\%); e a Central dos Sindicatos Brasileiros (CSB), a menor (queda de 85\%)" (Dieese, 2018, p. 5). Associa-se a isso, a queda mais significativa na taxa de sindicalização, que se reduziu para 12\% em 2018, e 11\%, em 2019, (PNADC-IBGE), quando os efeitos da reforma trabalhista sobre o mercado de trabalho e suas instituições (Justiça do Trabalho, sindicatos, órgãos de assessoria sindical) tornaram-se mais evidentes.

Além disso, vale recordar que, mesmo no período dos governos do PT, aproximadamente $40 \%$ dos sindicatos da CUT não possuíam registro sindical16 ou ainda estavam à espera do mesmo, ou seja, nesses sindicatos, a atuação se desenvolvia à margem da burocracia estatal, portanto sem acesso ao imposto sindical. Essa realidade atingia principalmente, em 2017, os ramos rural e municipal (Carvalho; Costa, 2019). Logo, depreende-se

${ }^{4}$ Em 2017, a CUT arrecadou 62,2 milhões e, em 2018, 3,4 milhões. Fonte: http://www. valor.com.br, acesso em 17/10/2019. 
que a tendência à institucionalização do imposto sindical na CUT esteve estreitamente relacionada à insuficiente arrecadação estatutária ${ }^{5}$ que não cobria despesas mensais dessa central.

Numa recente revisão da literatura internacional sobre a crise do sindicalismo, Costa et al. (2020) identificam alguns fatores que contribuem para a fragilização do sindicalismo, tais como: (i) fragmentação de interesses em torno da classe trabalhadora, provocada pela flexibilização dos mercados induzida pela lógica da globalização neoliberal e, podemos acrescentar, no caso brasileiro, a fragmentação de interesses entre as representações de classe, com ênfase na volátil política de unidade entre as centrais sindicais (Carvalho, 2013); (ii) crescente financeirização da economia em detrimento do valor do trabalho produtivo; (iii) vigência de práticas antissindicais; (iv) fragilização dos laços de solidariedade entre os trabalhadores e de confiança nas instituições sindicais; (v) perda de representatividade sindical associada à dificuldade de mobilização para a ação coletiva; (vi) limitado alcance das ações de caráter transnacional; (vii) proximidade com os partidos políticos e, a nosso ver, com os governos de coalizão com elos trabalhistas; e (viii) frágil aliança entre o sindicalismo, movimentos sociais e demais segmentos sociolaborais.

A nosso ver, o debate internacional sobre crise do sindicalismo, no caso brasileiro, deve ser compreendido à luz do contexto político pós impeachment de Dilma Rousseff que se afigura adverso para o sindicalismo em várias vertentes: política (governo Temer aprovou a reforma trabalhista e, com isso, promoveu uma rápida asfixia das finanças das entidades sindicais, e Bolsonaro que, ao rebaixar o Ministério do Trabalho para categoria de secretaria, fechou os canais de diálogo e participação institucional), econômica (inflexão dos indicadores econômicos), social (aumento do desemprego, mais precarização, menos oportunidades de integração

${ }^{5}$ Em 2008, a arrecadação mensal da CUT era de aproximadamente R $\$ 660$ mil, despesa fixa de R\$ 850 mil, o que representa um déficit mensal de R\$190 mil, sendo que o potencial de arrecadação era de R\$1,2 milhão. Vale dizer que, nesse período, a CUT cobrava $10 \%$ (receita bruta anual) de todas as organizações sindicais filiadas (Carvalho; Costa, 2019). 
social etc.) e jurídica (quadro normativo adverso) (Carvalho; Costa, 2019). Esse quadro de crise do sindicalismo brasileiro se defronta agora com o avanço da pandemia e das crises por ela geradas como, por exemplo, no âmbito do emprego.

Em maio de 2020, a taxa de desemprego era de aproximadamente $14 \%$ da população ativa na força de trabalho (PNADC, IBGE). Dentre os ocupados, isto é, dentre aqueles que permaneceram no emprego ou em atividade, 19\% estavam afastados do trabalho devido às medidas de distanciamento social (trabalho remoto, férias coletivas, suspensão dos contratos e licença remunerada). No mês de setembro, após a retomada gradual das atividades econômicas, esse afastamento temporário reduziu-se para $4 \%$ da população ocupada (PNADC-Covid, IBGE).

Quanto aos efeitos da pandemia nos salários e relações de trabalho, informações do Sistema Mediador (Brasil, Ministério da Economia) compiladas pelo Dieese (2020) indicavam que cerca de 36\% dos trabalhadores ocupados (30 milhões de pessoas) tiveram alguma perda no rendimento na comparação com a situação anterior. Também houve uma redução de 28\% (comparado a 2019) do número de cláusulas relativas a reajustes salariais e a tendência é adiar as negociações dos reajustes para o pós-pandemia. Cabe reforçar que a maioria das cláusulas negociadas teve relação direta com a Covid - 19, tratando de questões como a MP 936 sobre a suspensão do contrato de trabalho e redução de jornada e salários, que atingiu categorias importantes representadas pelas centrais sindicais, tais como: metalúrgicos, comerciários, trabalhadores dos transportes etc.

Feita essa introdução sobre a crise do sindicalismo pós-reforma trabalhista, na seção seguinte, analisamos o perfil dos dirigentes e, ainda, verificamos quais são as primeiras respostas sindicais da CUT frente à reforma trabalhista. Neste texto, utilizamos os resultados das pesquisas sobre o perfil socioeconômico dos dirigentes sindicais eleitos delegados (com poder de

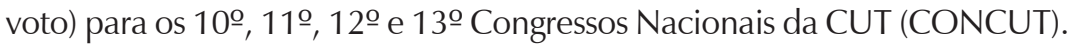
No entanto, salientamos que há limites tanto na continuidade das pesquisas 
como em relação à escolha dos temas e metodologias aplicadas, pois esses fatores estão relacionados com a organização que elabora a pesquisa (que é variável) e, principalmente, com o interesse da cúpula da instituição (Weber, 2009). Em geral, os resultados apontam uma imagem da composição social da CUT e o posicionamento dos dirigentes sindicais frente a temas estratégicos para essa central.

\section{Perfil dos delegados e resposta sindical frente à reforma trabalhista}

De acordo com as pesquisas CONCUT (CUT, 2010, 2013, 2016 e 2020), nos congressos realizados de 2009 a 2015, 80\% dos dirigentes sindicais eram diretores de sindicatos e, em 2019, esse número salta para $84,2 \%$. Quanto à liberação para a atividade sindical, a soma dos delegados liberados em tempo integral e parcial que, em 2009, representava 59,5\% do total de participantes, em 2019, alcança $66,2 \%$, ou seja, cresce quase 7 pontos percentuais. No que diz respeito ao tempo de militância no movimento sindical, há uma distribuição relativamente similar em décadas de atuação: "34,1\% atuam há mais de 20 anos, 33\% têm de 10 até 20 anos de militância sindical e outros 32,9\% atuam há até 10 anos, excluídos não respondentes. Do total de delegados/as entrevistados/as, em 2019, 8,1\% iniciaram sua militância nos últimos 4 anos" (CUT, 2020, p. 4).

Além disso, no 13ํㅡㄹ CONCUT (2019), 79,2\% dos funcionários públicos que participavam do congresso eram estatutários e 88,8\% dos que atuam no setor privado informaram ter contratos por prazo indeterminado, conforme prevê a CLT (CUT, 2020). Esses resultados demonstram que participa dos congressos da CUT uma "elite" sindical que representa uma parcela da classe trabalhadora que ainda está protegida por melhores contratos de trabalho e estabilidade, como no caso do servidor público estatutário, cujo peso nos congressos da CUT, principalmente dos ramos educação (setor público) e administração pública, é expressivo, conforme mostra a tabela 1 , a seguir. 
Tabela 1. Distribuição dos delegados por ramo, comparativo $10^{\circ}, 11^{\circ}, 12^{\circ}$ e e $13^{\circ}$ o CONCUT (\%)

\begin{tabular}{|c|c|c|c|c|}
\hline & $10^{\circ}$ CONCUT & $11^{\circ}$ CONCUT & $12^{\circ}$ CONCUT & 13 CONCUT \\
\hline & 2009 & 2012 & 2015 & 2019 \\
\hline Educação & 25,2 & 26,5 & 30,3 & 29,9 \\
\hline Rural & 18 & 14,3 & 15,7 & 12,3 \\
\hline $\begin{array}{l}\text { Administração } \\
\text { Pública }\end{array}$ & 8,1 & 7,2 & 6,4 & 7 \\
\hline Financeiro & 7,5 & 7,2 & 3,5 & 11,4 \\
\hline Metalúrgico & 6,6 & 6,9 & 5,8 & 5,7 \\
\hline $\begin{array}{l}\text { Comércio e } \\
\text { Serviços }\end{array}$ & 6 & 5,1 & 6,4 & 6,9 \\
\hline Seguridade Social & 5,1 & 4,8 & 6 & 5,5 \\
\hline Municipais & 4,2 & 4,7 & 5,7 & 4,5 \\
\hline Urbanitário & 3,8 & 3,4 & 2,7 & 2,7 \\
\hline Comunicação & 3,3 & 4 & 3,2 & 2,3 \\
\hline Químico & 3,1 & 2,8 & 3,3 & 3,5 \\
\hline Transporte & 2,4 & 2,8 & 1,7 & 1,5 \\
\hline $\begin{array}{l}\text { Construção e } \\
\text { Madeira }\end{array}$ & 2,1 & 3,5 & 2,8 & 1,4 \\
\hline Alimentação & 1,4 & 0,9 & 1,5 & 1,2 \\
\hline Aposentados & 1,2 & 1,5 & 1,2 & 1,8 \\
\hline Vestuário & 1,1 & 1,3 & 1,2 & 0,8 \\
\hline Sem resposta & 0,6 & 2,9 & 2,2 & 1,3 \\
\hline $\begin{array}{l}\text { Profissionais } \\
\text { Liberais }\end{array}$ & 0,3 & 0,2 & 0,4 & 0,3 \\
\hline Total & 100 & 100 & 100 & 100 \\
\hline
\end{tabular}

Fonte: CUT (2010), CUT (2013), CUT (2016) CUT (2020). Elaboração própria. 
De 2009 a 2019, o ramo da educação se mantém com o maior número de representantes nos congressos da CUT seguido pelo ramo rural. Podemos dizer que esse resultado é, de certa maneira, um retrato invertido do cadastro oficial da CUT em 2017. Ou seja, um pouco antes da reforma trabalhista, em número de sócios ${ }^{6}$, o ramo rural era o maior seguido pela educação (com ênfase nos sindicatos do setor público). No entanto, apesar desse aparente gigantismo dos trabalhadores rurais dentro da CUT, o fato é que, nos momentos decisórios, tais como os congressos, observa-se uma perda de protagonismo ao longo dos anos. Em 2009, o sindicalismo rural representava $18 \%$ do total de delegados e, dez anos depois, $12,3 \%$ dos participantes do CONCUT declaravam-se oriundos desse segmento.

A nosso ver, é provável que a pulverização dos sindicatos dos trabalhadores rurais da CUT - distribuídos basicamente entre a Confederação Nacional dos Trabalhadores na Agricultura (CONTAG), desfiliada da CUT em 2009, quando passou a funcionar a partir de um sistema de coordenação política compartilhado entre as centrais (Carvalho, 2013); a Confederação Nacional dos Trabalhadores e Trabalhadoras na Agricultura Familiar (CONTRAFBRASIL), criada em 2016 e filiada à CUT, porém sem registro sindical; e a Confederação Nacional dos Trabalhadores Assalariados Rurais (CONTAR), cuja origem remonta ao ano de 2015, com registro sindical em 2017, mas que, desde sua criação, encorpa o segmento do sindicalismo sem central - seja um fator que pode contribuir para a redução do poder estrutural, associativo e institucional (Costa et al., 2020) do ramo rural. Resultado que pode ter influenciado a redução da sua delegação ao 13을 CONCUT.

Outra dimensão do perfil dos dirigentes sindicais, estratégica nas análises sobre as perspectivas de revitalização sindical (Frege; Kelly, 2004), é a distribuição etária dos participantes. Leôncio Rodrigues (1990), quando analisou o perfil dos dirigentes no 3 ㅇ CONCUT (1988), mostrou que $75 \%$ dos delegados estavam concentrados nas faixas etárias entre 21 e 39 anos. O envelhecimento dos dirigentes sindicais foi uma tendência já apontada por Rodrigues (1997) quando analisou a composição social do 4을 CONCUT

${ }^{6}$ Ramo rural, 1487 sindicatos, 3.775 .744 sócios (35\% taxa média de sindicalização) e educação pública, 106 sindicatos, 928.801 sócios (49\% taxa média de sindicalização) (CUT, 2017). 
(1991). No período aqui analisado, vemos que essa tendência se confirmou e, conforme mostra a tabela 2, a faixa etária que tem predominância do $10^{\circ}$ CONCUT ao $12^{\circ}$ CONCUT é a de 36 a 54 anos.

No 13을 CONCUT, o último congresso realizado (2019), o envelhecimento ficou ainda mais evidente, uma vez que 56,4\% dos delegados têm entre 45 e 64 anos. Cabe destacar que, ao analisarmos os dois extremos da distribuição etária, enquanto o grupo de 55 a 64 anos cresce de forma contínua desde o 10을 CONCUT (Carvalho, 2014), saltando de 15\% em 2009 para 25,6\% em 2019, a presença de jovens (até 35 anos) nos congressos da CUT continua diminuindo, passando de 17,2\% em 2009 para 9,5\% em 2019. A partir desses resultados, verificamos que, dez anos após a criação da Secretaria Nacional de Juventude e as suas ramificações pelos estados, o efeito imediato é a criação de mais cargos de direção sem a necessária inclusão e vitalidade que os jovens podem impulsionar em espaços deliberativos (nesse caso, os congressos nacionais). Logo, a participação desse segmento segue como um desafio de renovação sindical (Carvalho, 2014) (Tabela 2).

Tabela 2. Distribuição dos delegados por faixa etária, comparativo $10^{\circ}$, $11^{\circ}$, $12^{\circ}$ e $13^{\circ}$ CONCUT (\%)

\begin{tabular}{|l|c|c|c|c|}
\hline \multicolumn{1}{|c|}{ Idade } & $\begin{array}{c}\mathbf{1 0} \\
\text { CONCUT } \\
\mathbf{2 0 0 9}\end{array}$ & $\begin{array}{c}\mathbf{1 1} \mathbf{0} \\
\text { CONCUT } \\
\mathbf{2 0 1 2}\end{array}$ & $\begin{array}{c}\mathbf{1 2} \mathbf{0} \\
\text { CONCUT } \\
\mathbf{2 0 1 5}\end{array}$ & $\begin{array}{c}\mathbf{1 3} \\
\text { CONCUT } \\
\mathbf{2 0 1 9}\end{array}$ \\
\hline Menos de 25 anos & 1,6 & 1,3 & 0,9 & 0,5 \\
\hline De 25 a 35 anos & 15,6 & 13,8 & 13,3 & 9 \\
\hline De 36 a 44 anos & 29,5 & 25,2 & 23,7 & 19,7 \\
\hline De 45 a 54 anos & 38,1 & 37,6 & 36,7 & 30,8 \\
\hline De 55 a 64 anos & 15 & 18,4 & 20,5 & 25,6 \\
\hline 65 anos ou mais & - & 3,5 & 4,3 & 6,3 \\
\hline Sem resposta & 0,2 & 0,2 & 0,6 & 8,1 \\
\hline Total & 100 & 100 & 100 & 100 \\
\hline
\end{tabular}

*No 10 o CONCUT não foi incluída a faixa 65 anos ou mais.

Fonte: CUT (2010), CUT (2013), CUT (2016) CUT (2020). Elaboração própria. 
Em relação à escolaridade, é possível notar um crescimento contínuo da participação dos delegados com ensino superior completo e pós-graduação. Conforme mostra a figura 1, já em 2009, esse grupo de dirigentes de elevada escolaridade representava $42,6 \%$ do total de delegados. Dez anos mais tarde, as informações do último congresso revelam que o percentual de delegados com diploma universitário aumentou para $64,8 \%$. Os resultados demonstram que os participantes dos congressos da CUT são diretores sindicais experientes, liberados parcialmente ou totalmente para a atividade sindical e com alto grau de escolaridade, estando à frente do aparato sindical. Vale lembrar que o ramo da educação foi a maior delegação em todos os congressos analisados, fato que pode ter contribuído para a elevação de escolaridade dos participantes (Carvalho, 2013, 2014).

Figura 1. Distribuição dos delegados por escolaridade, comparativo $10^{\circ}$, $11^{\circ}$, $12^{\circ}$ ㅇ e $13^{\circ}$ CONCUT

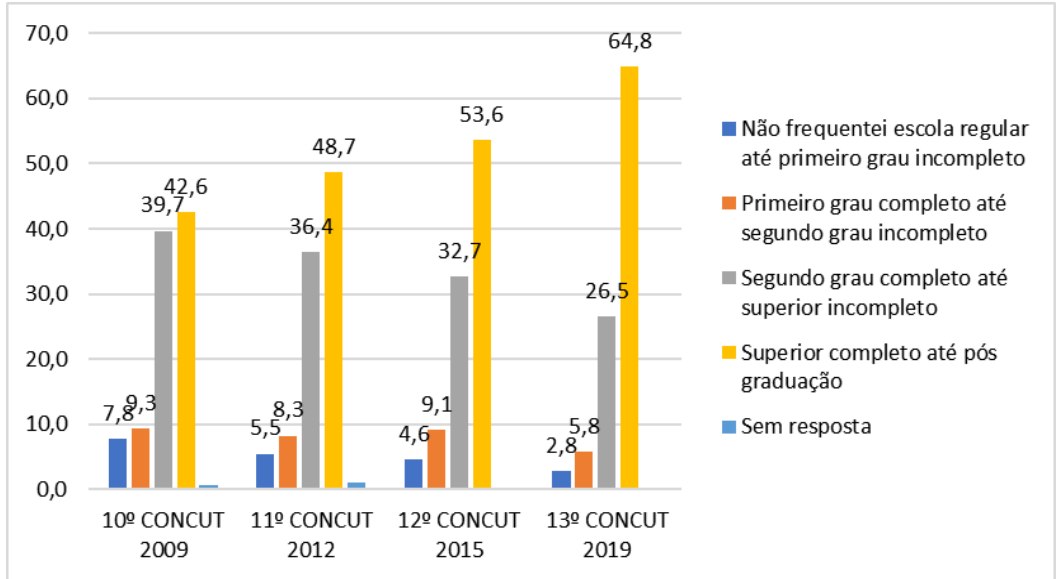

Fonte: CUT (2010), CUT (2013), CUT (2016), CUT (2020). Elaboração própria.

Quando perguntados sobre os principais impactos da reforma trabalhista, por ordem de prioridade, os delegados destacaram: 19) a perda de receita financeira $(68,6 \%) ; 2$ o $)$ aumento da precarização nas relações de 
trabalho (46,6\%); e 3 o) perda de filiados (44,6\%). Além disso, os dirigentes destacaram: 4 ) maior dificuldade de concluir acordos e convenções coletivas $(31,9 \%) ; 5$ 으 queda nas homologações acompanhadas pelo sindicato $(30,0 \%) ; 6^{-}$) alterações nas relações de trabalho sem negociação

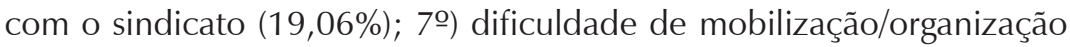
$\left.(1,4 \%) ; 8^{\circ}\right)$ outras alterações $(2,1 \%)$; e 9 ọ) não houve alteração significativa (0,9\%) (CUT, 2020, p. 8).

Ou seja, se antes, aparentemente, havia um "dilema" em relação à utilização do imposto sindical (Carvalho, 2013), com dirigentes que afirmavam no 10ํㅡㄹ CONCUT (2009) que a sustentação financeira deveria partir da mensalidade dos associados e da contribuição negocial (86\% e $31 \%$ respectivamente), após a reforma trabalhista, a maioria dos delegados sindicais reconhecem as dificuldades em superar as perdas de receita. Como se vê, a CUT e seus sindicatos confrontaram-se com um problema já alertado por Carvalho e Costa (2019), que está associado ao uso do imposto para ampliação e manutenção da sua estrutura (aquisição de carros, imóveis etc.), criação de secretarias, ${ }^{7}$ contratação de assessorias e profissionalização dos seus dirigentes, impulsionando um tipo de reorganização institucional sem a necessária ampliação da representação sindical pela base. Nesse sentido, entre os dirigentes sindicais que mencionaram a adoção por sua organização de medidas visando reduzir despesas, as respostas mais frequentes foram: corte de recursos para movimentos sociais e mobilizações (40,2\%), demissão de pessoal $(37,4 \%)$, redução de investimentos em comunicação (35,3\%), redução dos valores referente a contratos com assessorias jurídicas (22\%), redução do número de dirigentes liberados (19,8\%), redução de serviços aos associados $(14,7 \%)$, venda de patrimônio $(14,5 \%)$, fechamento de subsedes $(13,4 \%)$, compartilhamento de estrutura $(12,4 \%)$ e fusão com outros sindicatos (4,9\%) (CUT, 2020).

${ }_{7}$ Criação da Secretaria da Mulher em 2003; Saúde do Trabalhador; Meio Ambiente; Juventude e Promoção da Igualdade Racial em 2009 e, em 2015, a aprovação das Secretarias de Movimentos Sociais; Cultura e Jurídica, associada à criação da figura do Diretor Adjunto, que fez com que a Direção Executiva Nacional saltasse de 32 integrantes em 2012 para 50 em 2019 (CUT, 2012, 2019a). 
Em princípio, as medidas tomadas pela CUT e os sindicatos estão centradas em respostas tradicionais num cenário de crise financeira no qual se busca a redução do custeio da máquina sindical, fato comum no sindicalismo brasileiro. Vale recordar que, entre 2017 e 2018, mais de 8,3 mil postos de trabalho foram eliminados no conjunto das entidades sindicais (DIEESE, 2018). No caso da CUT, ainda que, desde 2017, a entidade busque atuar no combate à reforma trabalhista, ela vem aprovando sucessivas medidas que visam sua adequação ao novo cenário. Um exemplo dessa prática é o desligamento de funcionários numa primeira fase oferecendo bonificações através de um Processo de Desligamento Incentivado (PDI) e, mais recentemente, incentivando a pejotização do que resta do seu corpo funcional.

Conforme mostra a tabela 3, 74,3\% dos delegados do setor privado consideram a perda de filiados um dos principais efeitos da reforma trabalhista nos sindicatos. No setor rural, 64,2\% dos delegados também se mostraram preocupados com a queda na filiação, seguidos de $37,9 \%$ dos delegados do setor público em que os empregos e, consequentemente, os vínculos com os sindicatos tendem a ser mais estáveis (CUT, 2020).

Tabela 3. O seu sindicato está enfrentando perda de filiados em virtude da reforma trabalhista? (por setor de atividade do delegado) \%

\begin{tabular}{|l|c|c|c|c|c|}
\hline & Setor Público & $\begin{array}{c}\text { Setor } \\
\text { Privado }\end{array}$ & Setor Rural & $\begin{array}{c}\text { Setor público } \\
\text { e privado }\end{array}$ & Total \\
\hline Sim & 37,9 & 74,3 & 64,2 & 58,8 & 53,1 \\
\hline Não & 53,4 & 22,7 & 29,4 & 35,3 & 40,2 \\
\hline Não sabe & 8,7 & 3 & 6,4 & 5,9 & 6,7 \\
\hline
\end{tabular}

Fonte: CUT (2020). Elaboração própria.

Seguindo a classificação por ramos da CUT, o retrato cadastral um pouco antes da reforma trabalhista informava uma taxa média de sindicalização de aproximadamente 30\% (CUT, 2017). Resultado que se sustentava porque, no 
universo dos sindicatos da CUT, é possível encontrar "ilhas" de sindicalização, as quais envolvem, em geral, trabalhadores em condições ocupacionais mais estáveis como é o caso dos servidores públicos e dos segmentos com tradição no campo da negociação coletiva como, por exemplo, os seguintes ramos: educação (50\%), financeiro (69\%) e o urbanitário (64\%) (CUT, 2017).

No setor rural, de acordo com a CUT, em 2017, a taxa de sindicalização era de aproximadamente $36 \%$. Contudo, chama a atenção a baixa sindicalização dos ramos comércio e serviços (9,82\%) e vigilantes (23,83\%) (CUT, 2017). Vale dizer que, além de integrarem segmentos cuja característica é a fragilidade nas relações laborais e a baixa sindicalização, no caso da CUT, as disputas de base, envolvendo nomeadamente a Confederação dos Trabalhadores no Comércio e Serviços (CONTRACS) e a Confederação Nacional dos Vigilantes e Prestadores de Serviços (CNTV-PS) pela representação desses trabalhadores, podem ter contribuído para tal resultado.

Em um contexto de aprofundamento das mudanças no mundo do trabalho, associadas ao crescimento das empresas que se organizam em plataformas ou aplicativos digitais e às inovações tecnológicas da indústria 4.0 ou manufatura avançada - que automatizam processos, aproximam objetos físicos e virtuais e integram em rede as etapas de produção, comércio e serviços (Arbix et al., 2017) - a CUT assume o desafio de "elaborar um tipo de filiação específica para as trabalhadoras e os trabalhadores com contratos precários, especialmente, sem carteira, PJ, teletrabalho, aprendiz, intermitente e tempo parcial" (CUT, 2019b, p. 128).

Essa recente iniciativa da central pode ser compreendida como uma tentativa de responder à perda de filiados (tabela 3) e, também, de potencializar os recursos de poder sindical (Costa et al.,2020), por meio da diversificação da sua composição social. Afinal, dificilmente uma central da dimensão da CUT permanecerá alheia por muito tempo ou deixará de ser influenciada pelas novas e independentes formas de representação de trabalhadores (por fora da estrutura sindical), que se esboçam no Brasil e no mundo, todas procurando responder ao intenso processo de corrosão dos direitos sociais do trabalho que atinge o infoproletariado ou ciberproletariado (Filgueiras; Antunes, 2020). 
Por fim, a figura 2 mostra o conhecimento dos delegados sobre as principais ações que foram debatidas e/ou concretizadas em resposta à reforma trabalhista. Do total de participantes que responderam "sim", as opções mais destacadas por ordem de prioridade foram: 1ํ) eleição de representante no local de trabalho (48,5\%); 2 ㅇ) alterações estatutárias (34,1\%); 3으) articulação com entidades sindicais internacionais (18,4\%); 4ㅇ)

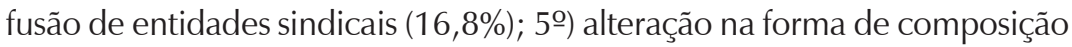
da direção (14,9\%); e 6 을 criação de sedes e subsedes coletivas com outras entidades (10,4\%) (CUT, 2020). Contudo, analisando o total de respondentes, com exceção das opções "eleição de representante no local de trabalho" e "alterações estatutárias", nas demais alternativas, o que prevalece é a resposta "não" para os debates e elaboração de estratégias que exigem alterações de fundo no modo como se organiza e estrutura um sindicato, como, por exemplo, a fusão de entidades sindicais (Figura 2).

Figura 2. Iniciativas organizativas debatidas e/ou adotadas pelos sindicatos segundo setor de atividade do delegado (\%)

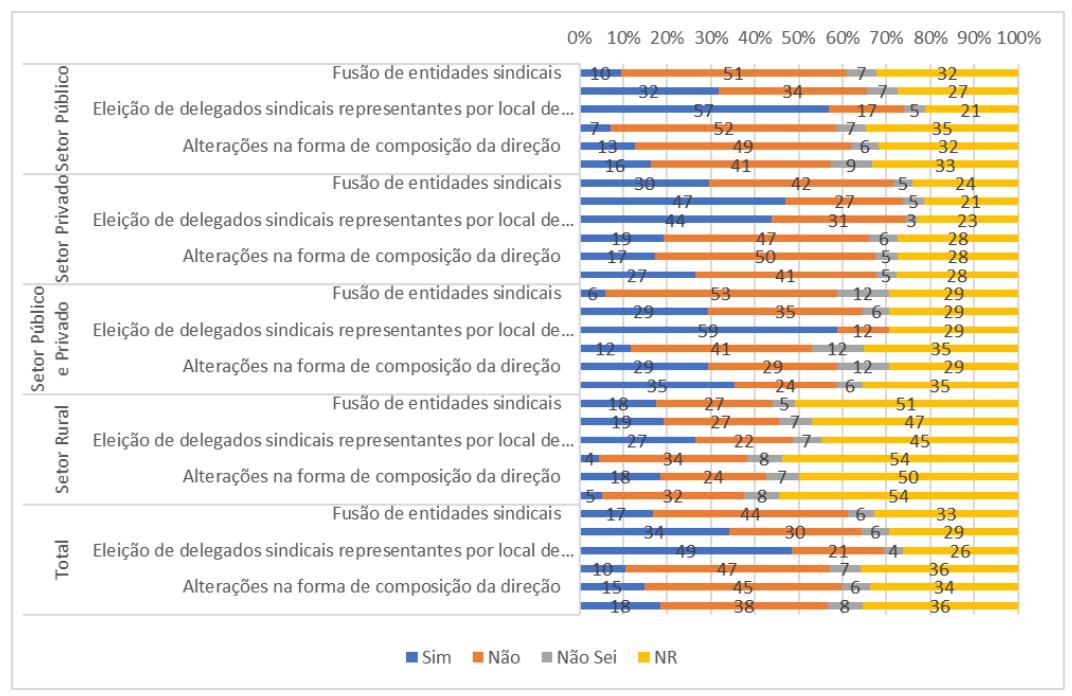

Fonte: CUT (2020). 
Logo, apesar da declarada perda de arrecadação financeira, verificamos que os procedimentos relativos à fusão ou incorporação sindical, conforme normatizava a Portaria de $\mathrm{n}=501^{8}$, foi uma alternativa pouco citada entre os dirigentes sindicais. Numa primeira análise, podemos considerar que a cultura sindical corporativista, a posição política da CUT marcada pela oposição aos governos Temer e Bolsonaro, o rebaixamento do Ministério do Trabalho ao status de secretaria e a inserção da política de registro sindical num outro "lugar" (circunscrita ao Ministério da Justiça) e patamar - afinal, agora, o registro já não conta mais para a aferição da representatividade sindical -, assim como a distribuição do imposto sindical (extinto pela reforma trabalhista) e dos dirigentes sindicais em espaços de representação (conselhos, comissões etc.) são os fatores que estão a reconfigurar as relações entre o sindicalismo e a política no contexto pós-impeachment.

Com relação ao fim da unicidade sindical, a pesquisa aplicada no 13음 CONCUT apresentou resultados contraditórios em relação à tendência verificada nos congressos anteriores. Se, nos 10ㅇ (2009), 11으 (2012) e 12o CONCUT (2015), a maioria dos delegados se disseram "a favor da ratificação da Convenção 87 da OIT" (57\%, 84,6\% e 79\% respectivamente), no 13o CONCUT, a situação se inverteu e os delegados posicionaram-se da seguinte maneira: 32,8\% contra o fim da unicidade, 22\% não responderam, 19,9\% sem posição definida, 10,0\% defendem o pluralismo com exclusividade de negociação pelo sindicato mais representativo e 9,3\% pelo fim da unicidade sindical (CUT, 2020).

A perda de protagonismo político das centrais, a crise financeira e o aumento da insegurança dos trabalhadores podem favorecer uma mudança de tendências, contudo essa alteração abrupta na posição dos sindicalistas deve ser analisada com cautela. Recorde-se que, de 2009 a 2015, a CUT perguntava a opinião dos delegados em relação à Convenção 87 da OIT.

${ }^{8}$ A Portaria no 501, publicada pelo Ministério da Justiça e Segurança Pública em 30/04/2019, foi substituída pela Portaria no 17.593, de 24/07/2020, agora subscrita pelo Ministério da Economia. 
Já em 2019, a pergunta versava sobre "uma eventual mudança na forma de organização sindical". Essa alteração no formato do questionamento, associada a um contexto pós-impeachment, adverso ao movimento sindical, certamente contribuiu para tal alteração no 13으 CONCUT.

Embora seja difícil avaliar o quanto as mudanças pontuais no questionário tenham prejudicado a discussão sobre a reforma da estrutura sindical e de seus pilares jurídicos, como a questão da unicidade, é certo que esse tema voltará em breve à agenda política de parlamentares e lideranças sindicais. Um exemplo disso é que, no momento da realização do 13ㅇ CONCUT (quando os questionários foram aplicados), o governo Bolsonaro havia recém instituído o Grupo de Altos Estudos do Trabalho - GAET, nomeando juristas, acadêmicos e representantes ligados a setores empresariais, excluindo as centrais sindicais de um espaço cujo objetivo era tratar de temas cruciais para o futuro do sindicalismo, tais como: negociação coletiva, organização e liberdade sindical.

\section{Considerações finais}

Desde a crise política e econômica de 2015, cujos efeitos repercutem até hoje na sociedade brasileira, o sindicalismo da CUT encontra dificuldades para ampliar sua base de trabalhadores filiados, conter a perda de direitos e manter a capacidade de influenciar os rumos da política econômica e setorial por meio da participação nos conselhos de desenvolvimento que, após o impeachment, foram gradualmente fragilizados e, em grande medida, extintos por decreto sancionado em 2019, já na gestão de Jair Bolsonaro.

De acordo com as seções anteriores deste artigo, argumentamos que parte das dificuldades em recrutar e mobilizar trabalhadores, aumentar a participação e as organizações no local de trabalho - dificuldades essas existentes desde o final dos anos 1990 - foram em certa medida compensadas, no caso da CUT, pelas ações baseadas no sindicalismo cidadão e apoio à luta por direitos sociais mais amplos. Essas, além de manter o prestígio social do movimento sindical com a chegada do PT à presidência da República, influenciaram o desenho de políticas públicas 
de amplo alcance, como a política de valorização do salário-mínimo; a ampliação da transferência de renda e do crédito; a política de compras governamentais e apoio à agricultura familiar.

A partir do golpe parlamentar de 2016, da reforma trabalhista de viés liberal, das políticas de austeridade e do "desmonte" dos espaços de participação social, é possível verificar uma tentativa da CUT de ampliar as ações de rua e retomar um discurso que, além de crítico, se coloca em oposição às diretrizes do governo federal. Contudo, ao compararmos o perfil dos delegados sindicais, notamos que existe uma continuidade da tendência de envelhecimento dos delegados, de aumento da escolaridade e da participação de funcionários públicos estatutários ou assalariados do setor privado com contratos CLT por tempo indeterminado.

A crescente distância entre o perfil dos delegados sindicais e aquele da maioria dos trabalhadores brasileiros, caracterizado pela elevada rotatividade, recorrentes períodos de desemprego e informalidade - num contexto de prolongada crise econômica agravada pela pandemia e o consequente aumento do desemprego de longa duração, do trabalho informal, do trabalho por aplicativos ou plataformas digitais, combinado com as dificuldades financeiras impostas pela Reforma -, tem realçado as dificuldades latentes enfrentadas pelo movimento sindical (como o crescente distanciamento da base, adesão dos trabalhadores aos valores da sociedade do consumo e ao discurso da autoiniciativa empreendedora). Ao mesmo tempo, gerou novas dificuldades, como as limitações ao financiamento de protestos, ações de rua, atividades de formação, assessoria política e econômica das lideranças.

Certamente, é preciso aprofundar a discussão e problematizar, em trabalhos de abordagem qualitativa, o perfil dos delegados sindicais e os seus efeitos na disposição dos sindicatos em promover processos de revitalização sindical (questões essas que fogem ao escopo deste artigo). Por enquanto, desenharemos no horizonte alguns desafios de renovação da composição social do sindicalismo ligado à CUT, nesse caso, com foco em alguns dos recursos de poder e modos de mobilização conforme a tipologia de Costa et al. (2020). 
1. Poder Societal - Direcionar a ação sindical para além das estratégias clássicas de mobilização no local de trabalho, buscando melhor combinar as lutas corporativas e as lutas gerais, retomando a "discussão sobre um projeto de sistema democrático de relações de trabalho, concebido como parte de um projeto mais amplo de desenvolvimento sustentável e com justiça social para o país" (Véras de Oliveira, 2020, p. 12), a partir do fortalecimento das ações sindicais integradas em rede (network embeddedness) como um meio de "disputa pela hegemonia da mudança societal e laboral" (Costa et al., 2020, p. 39). No caso da CUT, a ação sindical em rede foi ampliada em função da pandemia (através da organização de lives, reuniões de direção, atos políticos, ações de pressão sobre o congresso nacional etc., sempre em formato digital), com a divulgação das campanhas em que a CUT participa, tais como: a agenda cidadã que se expressa, por exemplo, a partir das plataformas eleitorais (Carvalho; Costa, 2019); \#600 pelo Brasil em defesa do auxílio emergencial no valor de 600 reais, entre outras ações realizadas nas esferas nacional e internacional.

2. Poder Associativo - Trata da ampliação da representação através do incremento no número de filiados e sócios, com diversificação e reforço da composição social dos sindicatos e com a abertura a segmentos sociolaborais não organizados (jovens, migrantes etc.), trabalhadores uberizados em geral. Ao lado disso, é preciso seguir diversificando e avançando no atendimento das demandas referidas aos negros, às mulheres, à comunidade, à preservação do meio ambiente etc., buscando melhor associar as lutas por reconhecimento das diferenças com as lutas por distribuição das riquezas (Véras de Oliveira, 2020).

Em última instância, a reversão da atual tendência de precarização estrutural do trabalho e a construção de nova utopia do trabalho é definida na disputa política e na correlação de forças que seja capaz de colocar em 
movimento todos os atores sociais que lutam pela transformação social (Krein et al., 2020). Para isso, a renovação da composição social dos sindicatos, o reforço da solidariedade interna, o uso eficiente de recursos infraestruturais, financeiros e o fomento a experiências organizativas inovadoras (Costa et. al, 2020) poderá ser uma direção no sentido de consolidar o sindicalismo brasileiro (neste caso da CUT, que foi objeto preferencial de tratamento neste artigo) como um ator social de relevo na construção dessa agenda positiva para o trabalho num cenário pós-pandemia.

Fernanda Forte de Carvalho é Professora Adjunta no Departamento de Ciências Sociais da Universidade Estadual de Londrina - UEL. Mestre e Doutora em Sociologia pela Faculdade de Economia da Universidade de Coimbra, na especialidade de Relações de Trabalho, Desigualdades Sociais e Sindicalismo.

$\triangle$ fernadaforte@uel.br

Jonas Tomazi Bicev é Doutor em Sociologia pela Universidade de São Paulo (2019). Pesquisador junto ao Centro de Estudos da Cultura Contemporânea (CEDEC).

$\bowtie$ Jonas.bicev@yahoo.com.br

\section{Referências}

1. ANTUNES, Ricardo. Trabalho intermitente e uberização do trabalho no limiar da indústria 4.0. In: ANTUNES, Ricardo (org.). Uberização, trabalho digital e Indústria 4.0. São Paulo: Boitempo, 2020. p. 11-22.

2. ANTUNES, Ricardo. O novo sindicalismo no Brasil. Campinas: Pontes, 1995.

3. ANTUNES, Ricardo; SILVA, Jair B. Para onde foram os sindicatos? Do sindicalismo de confronto ao sindicalismo negocial. Caderno $C R H$, v. 28, n. 75, p. 511-527, 2015. https://doi.org/10.1590/S0103-49792015000300005

4. ARBIX, Glauco; SALERNO, Mario Sergio; ZANCUL, Eduardo; AMARAL, Guilherme; LINS, Leonardo M. O Brasil e a nova onda de manufatura avançada: $\mathrm{O}$ que aprender com Alemanha, China e Estados Unidos. Novos estudos CEBRAP, v. 36, n. 3, p. 29-49, nov. 2017. https://doi.org/10.25091/S0101$\underline{3300201700030003}$

5. AVRITZER, Leonardo. O pêndulo da democracia. São Paulo: Todavia, 2019.

6. CARDOSO, Adalberto M. Dimensões da crise do sindicalismo brasileiro. Caderno CRH, v. 28, n.75, p. 493-510, 2015. https://doi.org/10.1590/S0103$\underline{49792015000300004}$ 
7. CARVALHO, Fernanda F. de. CUT no início do século XXI: Perfil dos dirigentes e desafios da ação sindical. Revista Brasileira de Sociologia, v. 2, n. 04, p.135-158, 2014. https://doi.org/10.20336/rbs.80

8. CARVALHO, Fernanda F. de. Os dilemas da CUT no início do século XXI: rumo a uma nova institucionalização sindical? 2013. Tese (Doutorado em Sociologia) Faculdade de Economia, Universidade de Coimbra, Portugal, 2013.

9. CARVALHO, Fernanda F. de; COSTA, Hermes A. A relação do sindicalismo CUT com o governo: dilemas e perspectivas (2003-2016). Revista de Ciências Sociais Política \& Trabalho, n. 49, p. 170-187, 2019. https://doi.org/10.22478/ ufpb.1517-5901.2018v1n49.34995

10. CARVALHO, Guilherme. A representação da CUT no Governo Lula (20032010). São Paulo: Editora da Unesp, 2014.

11. COSTA, Hermes Augusto; ESTANQUE, Elísio; FONSECA, Dora; SILVA, Manuel C. Poderes sindicais em debate: desafios e oportunidades na Autoeuropa, TAP e PT/Altice. Coimbra: Almedina, 2020.

12. CUT - Central Única dos Trabalhadores. Relatório da pesquisa de perfil dos delegados das entidades filiadas à CUT. 13 CONCUT. São Paulo: CUT, 2020.

13. CUT - Central Única dos Trabalhadores. Estatuto da Central Única dos Trabalhadores. Aprovado no 13o CONCUT (2019). São Paulo: CUT, 2019a.

14. CUT - Central Única dos Trabalhadores. Resoluções do $13^{\circ}$ CONCUT. São Paulo: CUT, 2019b.

15. CUT - Central Única dos Trabalhadores. Panorama dos ramos da CUT e estratégias de fortalecimento do projeto político organizativo. Subsídio 1. CNM/ CUT. São Paulo: CUT, 2017.

16. CUT - Central Única dos Trabalhadores. Quem são e o que pensam os delegados do $12^{\circ}$ CONCUT. São Paulo: CUT, 2016.

17. CUT - Central Única dos Trabalhadores. Perfil dos delegados e das delegadas do $11^{\circ}$ CONCUT. São Paulo: CUT, 2013.

18. CUT - Central Única dos Trabalhadores. Estatuto da Central Única dos Trabalhadores. São Paulo: CUT, 2012.

19. CUT - Central Única dos Trabalhadores. Quem são e o que pensam os delegados e as delegadas do $10^{\circ}$ CONCUT. São Paulo: CUT, 2010.

20. CUT - Central Única dos Trabalhadores. Resoluções do $4^{\circ}$ CONCUT. São Paulo: CUT, 1991.

21. DIEESE - Departamento Intersindical de Estatística e Estudos. De olho nas negociações. Boletim no 1. São Paulo: Dieese, agosto de 2020.

22. DIEESE - Departamento Intersindical de Estatística e Estudos. Subsídios para o debate sobre a questão do financiamento sindical. Nota técnica no 200. São Paulo: Dieese, dezembro de 2018. 
23. DIEESE - Departamento Intersindical de Estatística e Estudos. A reforma trabalhista e os impactos para as relações de trabalho no Brasil. Nota Técnica, n. 178. São Paulo: Dieese, 2017.

24. FILGUEIRAS, Vitor; ANTUNES, Ricardo. Plataformas digitais, uberização do trabalho e regulação no capitalismo contemporâneo. In: ANTUNES, Ricardo (Org.). Uberização, trabalho digital e Indústria 4.0. São Paulo: Boitempo, 2020. p. 59-78.

25. FREGE, Carola M.; KELLY, John (Org.). Varieties of unionism: strategies for union revitalization in a globalizing economy. Oxford: Oxford University Press, 2004.

26. GALVÃO, Andréia. A reconfiguração do movimento sindical no governo Lula. Revista Outubro, n. 18, p. 175-197, 2009.

27. GALVÃO, Andréia. O movimento sindical frente ao governo Lula: dilemas, desafios e paradoxos. Outubro Revista, ed. 14, p. 131-150, 2006.

28. GALVÃO, Andréia et al. Dossiê reforma trabalhista. Campinas: Cesit/ie/Unicamp, 2017. Disponível em: http://www.cesit.net.br/dossie-reforma-trabalhista/.

29. GUMBRELL-MCCORMICK, Rebecca; HYMAN, Richard. Trade unions in Western Europe: hard times, hard choices. Oxford: Oxford University Press, 2013.

30. KLOOSTERBOER, Dirk. Estratégias sindicais inovadoras. Lisboa: Instituto Ruben Rolo, 2008.

31. KREIN, José D. O desmonte dos direitos, as novas configurações do trabalho e o esvaziamento da ação coletiva: consequências da reforma trabalhista. Tempo Social, v. 30, n. 1, p. 77-104, 2018. https://doi.org/10.11606/0103-2070. ts.2018.138082

32. KREIN, José D.; DIAS, Hugo. The CUT's experience during the Workers' Party governments in Brazil (2003-2016). Global Labour Journal, v. 9, n. 2, p. 199-214, 2018. https://doi.org/10.15173/glj.v9i2.3342

33. KREIN, José D.; TEIXEIRA, Marilane; MANZANO, Marcelo. Utopias do trabalho: desafios e perspectivas para o pós pandemia. São Paulo: Fundação Friedrich Ebert Brasil, dezembro de 2020.

34. LADOSKY, Mario H.; RODRIGUES, Iram J. A CUT e o sindicalismo brasileiro nos anos recentes: limites e possibilidades. Tempo Social, v. 30, n. 1, p. 53-76, 2018. https://doi.org/10.11606/0103-2070.ts.2018.138079

35. LOPES NETO, Sebastião; GIANOTTI, Vito. Para onde vai a CUT? São Paulo: Scritta Editorial, 1993.

36. MELLO E SILVA, Leonardo. A generalização difícil: a vida breve da Câmara Setorial do Complexo Químico seguida do estudo de seus impactos em duas grandes empresas do ramo. São Paulo: Annablume, 2000.

37. NASCIMENTO, Cláudio. Sindicato-cidadão. Florianópolis: UFSC, 1998. Mimeografado. 
38. OLIVEIRA, Carlindo R. de; AUGUSTO JR., Fausto; COSTA, Luis Augusto R. da. Sistema Brasileiro de Relações de Trabalho: das origens à reforma (anti) trabalhista de 2017 e seus primeiros impactos. In: RODRIGUES, Iram J. (Org.). Trabalho e ação coletiva no Brasil: contradições, impasses e perspectivas (1978-2018). São Paulo: Annablume, 2019. p. 385-410.

39. RODRIGUES, Eduardo M.; SILVA, Gerardo A.; SILVA, Sidney J. da. 40 anos do novo sindicalismo no $\mathrm{ABC}$ paulista: da lógica do confronto à lógica da rede. In: RODRIGUES, Iram J. (Org.). Trabalho e ação coletiva no Brasil: contradições, impasses, perspectivas (1978-2018). São Paulo: Annablume, 2019. p. 359-383.

40. RODRIGUES, Iram J. Sindicalismo e política. A trajetória da CUT. São Paulo: Scritta, 1997.

41. RODRIGUES, Iram J.; LADOSKY, Mário; BICEV, Jonas T. Sindicalização e representatividade das centrais sindicais no Brasil. Trabajo e Sociedad, n. 27, p. 43-62, 2016.

42. RODRIGUES, Leôncio M. Destino do sindicalismo. São Paulo: Editora da Universidade de São Paulo, 2002.

43. RODRIGUES, Leôncio M. CUT: os militantes e a ideologia. Rio de Janeiro: Paz e Terra, 1990.

44. SADER, Eder. Quando novos personagens entraram em cena: experiências, falas e lutas dos trabalhadores da Grande São Paulo, 1970-80. Rio de Janeiro: Paz e Terra, 2001.

45. SANTOS, Wanderley G. A democracia impedida: o Brasil no século XXI. FGV Editora. Edição do Kindle, 2017.

46. SIMÃO, Azis. Sindicato e Estado: suas relações na formação do proletariado de São Paulo. São Paulo: Hucitec, 2012.

47. VÉRAS DE OLIVEIRA, Roberto. Sindicalismo e democracia no Brasil: atualizações - do Novo Sindicalismo ao Sindicato Cidadão. 2002. Tese (Doutorado em Sociologia) - Universidade de São Paulo, São Paulo, 2002.

48. VÉRAS DE OLIVEIRA, Roberto. Sindicalismo brasileiro: que caminhos seguir? São Paulo: Fundação Friedrich Ebert Brasil, 2020.

49. WEBER, Max. Economia e sociedade: fundamentos da sociologia compreensiva. 4. ed. Brasília: Editora da Universidade de Brasília, 2009. (v. 1).

50. WEBER, Max. Os três tipos puros de dominação legítima. In: WEBER, Max. Sociologia. 7. ed. São Paulo: Atica, 2008. (Coleção Grandes Cientistas Sociais, n. 13). 
